\title{
Representación, perspectiva y fauna en la escuela cusqueña: un estudio de caso
}

\section{Representation, perspective and fauna in the Cusco school: a case study}

\author{
Roberto Juan Katayama Omura ${ }^{1}$, Víctor Pulido Capurro ${ }^{2}$, \\ Dionicia Lizbeth Pedrosa Velasco, ${ }^{3}$ Edith Olivera Carhuaz ${ }^{4 a}$ \\ Universidad Nacional Mayor de San Marcos, Lima, Perú ${ }^{13}$ \\ Universidad Privada San Juan Bautista, Lima, Perú ${ }^{2}$ \\ Universidad Jaime Bausate y Meza, Lima, Perú ${ }^{4}$ \\ Orcid ID: https://orcid.org/0000-0002-9238-5387 1 \\ Orcid ID: https://orcid.org/0000-0002-4788-1162 \\ Orcid ID: https://orcid.org/ 0000-0003-3589-3438 3 \\ Orcid ID: https://orcid.org/0000-0002-7400-8625
}

Recibido: 17 de mayo de 2021

Aceptado: 03 de setiembre de 2021

\section{Resumen}

La naturaleza simbólica de los cuadros de la pintura de la Escuela Cusqueña interpreta la concepción del espacio pictórico, en su representación en la pintura, el tipo de perspectiva y la fauna, tomando como caso de análisis el cuadro "La última comunión de Santa María Egipcíaca". Para ello, se estudia el sentido de la representación, el tipo de perspectiva, la distribución dentro del espacio pictórico y se complementa con la identificación de las especies de aves representadas en el mencionado cuadro. El análisis de la representación espacial, implícita en el cuadro, emplea el método de análisis formal. El enfoque de este estudio es cualitativo descriptivo y el diseño metodológico asume la perspectiva desde la vertiente transdisciplinar, pues se basan en la Historia del Arte Virreinal Peruano, el análisis iconográfico, el análisis iconológico, así como la taxonomía y sistemática ornitológica.

Palabras claves: Escuela cusqueña, representación, perspectiva, fauna, aves, pintura, arte.

\begin{abstract}
The symbolic nature of the paintings of the Cusco School interprets the conception of the pictorial space, in its representation in the painting, the type of perspective and the fauna, taking as a case of analysis the painting "The Last Communion of Santa María Egipcíaca." To do this, the meaning of the representation, the type of perspective, the distribution within the pictorial space is studied and it is complemented with the identification of the bird species represented in the aforementioned painting. The analysis of the spatial representation, implicit in the
\end{abstract}


picture, uses the formal analysis method. The focus of this study is qualitative-descriptive and the methodological design assumes the perspective from the transdisciplinary perspective, since they are based on the History of Peruvian Viceregal Art, iconographic analysis, iconological analysis, as well as taxonomy and ornithological systematics.

Keywords: Cusco School, representation, perspective, fauna, birds, painting, art.

\section{Introducción}

La perspectiva o modo de representar la realidad en el arte, ha sufrido una serie de cambios, desde una concepción mágico religiosa en sus orígenes, hasta una subjetiva y humanista en esta época contemporánea, donde como han propuesto sociólogos y filósofos la concepción de la realidad es fruto de la construcción social, (Berger \& Luckmann, 1972). En ese sentido, la concepción que sobre el espacio ha tenido al ser humano al crear obras de arte, puede sistematizarse en tres modos: la aspectiva, la prospectiva y perspectiva. La primera tiene dos variantes: la naturalista y la geométrica.

La flora y la fauna, especialmente las aves, resaltan en las pinturas, no sólo por poseer un significado simbólico sino también práctico, pues permiten al espectador ubicar, con la ayuda del paisaje, a la representación en un contexto geográfico específico. En ese sentido, el Perú ha sido reconocido desde tiempos inmemoriales por la riqueza de su diversidad biológica: entre la fauna solamente la de vertebrados, que es la taxonómicamente mejor conocida, registra 5,735 especies (Walker, 2015). A este grupo de vertebrados pertenecen las aves, con 1,878 especies, lo que ubica a nuestro país como el segundo en número de especies en el mundo. Solo para la Región Cusco se estima que existen alrededor de 600 especies de aves; casi un tercio del total de especies que tiene el Perú (Walker, 2015; Venero, 2019). Por lo tanto, cobra especial relevancia el estudio de las aves representadas en los cuadros de la Escuela Cusqueña, pues no hay investigaciones previas que hayan estudiado sistemáticamente y menos aún relacionado la fauna que figura en los cuadros, con la representación espacial utilizada por el artista.

A la luz de este contexto, la presente investigación revela la naturaleza simbólica de la pintura cusqueña, interpreta la concepción del espacio pictórico al interior del cual se enmarca lo representado en la pintura y, finalmente, se establece la procedencia geográfica de las aves que figuran en el cuadro "La última comunión de Santa María Egipcíaca" (ca. 1720/1750), de autor anónimo.

\section{Método}


Para el estudio del sentido de la representación, el tipo de perspectiva y la distribución dentro del espacio pictórico se recure al análisis de la representación espacial, implícita en el cuadro, para el que se emplea el método de análisis formal (Hausser, 1977; Wölfflin, 1979; Panofsky 1980 y 2016; Gombrich, 2002). El objeto de estudio cumple con la regla de la variación estructural de las perspectivas, por lo que estos métodos permiten, tomando como base los tres tipos de representación descritos en dichas obras (aspectiva, prospectiva o perspectiva) determinar a cuál corresponde la representación estudiada en el cuadro. El enfoque es cualitativo y el diseño metodológico de carácter descriptivo (Hernández \& Mendoza, 2018), asume la perspectiva desde la vertiente transdisciplinar pues se basan en la Historia del Arte Virreinal Peruano, el análisis iconográfico, el análisis iconológico, así como la taxonomía y sistemática ornitológica. Para ello, se presenta las características distintivas de cada tipo de representación para luego compararlas con las características de la representación pictórica del cuadro estudiado.

Para la identificación de las aves se utilizó las guías de identificación de campo de Venero (2019) y Walker (2015). Posteriormente, se efectuó la comparación de las siluetas tomando como base las características básicas resaltantes de la morfología externa de las especies de aves; para sobre esas evidencias proceder a la identificación de las mismas. Dado que las figuras de las aves son representaciones pictóricas idealizadas solo se pudo llegar a una aproximación en la identificación de las especies.

\section{Bases teóricas}

\section{La pintura cusqueña como representación y como símbolo}

La presente investigación, por su carácter interdisciplinar, carece de antecedentes directos. Sin embargo, sobre el tema de la naturaleza del arte se tiene, entre otras, las obras de Danto (2013) y Eco (2013). Sobre la perspectiva, están los estudios de Hausser (1977); Wölfflin (1979); Panofsky (1980) y Panofsky (2016). En cuanto a la evolución de las escuelas artísticas están las obras de Caralt y Casal (2012); Pomella (2004) y Rovira (2010), entre otras. Sobre el llamado "Barroco Andino" los estudios de Gisbert (1999) y con relación a la Escuela Cuzqueña es ineludible la obra de Stastny (2013).

En la actualidad, somos deudores del paradigma contemporáneo que considera a la pintura como una creación individual del artista, sin embargo, esta concepción tiene apenas más de un siglo y se iniciaría con las vanguardias europeas como el fauvismo, cubismo, 
maquinismo, etc. Este no sería el caso de la Escuela Cusqueña. Para comprender su sentido, será necesario remontarnos a la historia de la mentalidad artística.

Desde Platón hasta la Edad Media, se pensaba que la pintura debería ser una suerte de mímesis o imitación lo más fiel de la realidad. Esto lo vemos en el Ión donde se sostiene que el poeta no conoce la realidad, sino que sólo es un inspirado que la copia (von Der Walde, 2006, p. 6). Posteriormente en La República, Platón asumirá que no existe lo que llamaríamos hoy creación artística, sino que el artista sólo copia, el pintor imita la realidad sensible; esto es, lo que perciben nuestros sentidos (Del Valle, 2013, pp. 155-162). En la Edad Media europea con el dominio ideológico del cristianismo, el artista dejará de lado la realidad sensorial y mundana para representar el imaginario religioso católico. Será pues entonces, que en el medioevo la imaginación del artista despegará y comenzará a cobrar autonomía respecto a la realidad sensible. La mejora, la estiliza, la eleva (Montes de Oca, 2010). Sin embargo, no debe esto interpretarse en el sentido de un artista creador, sino más bien de un artista que busca representar la verdadera realidad, que es el imaginario religioso imperante. Recién con el Renacimiento es que se comenzará a difundir el paradigma del artista como creador y la pintura como creación, cambio paradigmático que culminará en el siglo XIX con la tesis de lo bello y lo sublime (Panofsky, 2016, pp. 29-59).

Lo cierto es que las obras de arte son un producto histórico, circunscritas en su producción, a un espacio-tiempo determinado; es un signo-símbolo y, como sostiene la semiótica, todo símbolo posee un significado social, histórico y cultural. Es decir, lo que está en lugar de otra cosa, que hace las veces de ella. La cosa representada es el significado. "Los signos son usados por los que pertenecen a una comunidad semiótica pues tienen que compartirlos para saber, primero, que son signos y, después, cuál es su significado" (Beuchot, 2009, p. 7).

Pero en la medida que la comunicación es a través de un "símbolo", esta comunicación, así como el mensaje codificado por el artista no es directa, sino ambigua, debiendo ser reconstruida en su significatividad por el receptor o decodificador (Eco, 2013). Esto supone que para que un signo-símbolo tenga sentido tanto el emisor, en este caso el artista como el receptor, en este caso el comitente o quien encargó la obra, así como el espectador o quien contempla la obra deben compartir un universo significativo y simbólico, caso contrario no habría comunicación alguna. Claros ejemplos en la dirección mencionada por Eco son las definiciones de arte que ofrece Danto (2013). El arte, así, es un tipo de "símbolo". Pero ¿qué tipo de símbolo?, ¿en qué sentido debemos situar el significado de "encarnado"? Esto nos lleva, nuevamente, a contextos de habla y significatividad. El mismo término que se utiliza para 
referirse a las obras de arte y más aún la categoría, dentro de la cual la insertamos la categoría "arte", obedece también a un mundo de la vida con una historia acontecida que las determinan y las definen temporalmente. Hasta el siglo XIX esas reglas o eran creadas y fijadas por una élite que tenía acceso a cierto tipo de entes llamados "obras de arte". Eran estas élites de artistas, mecenas, comitentes e instituciones los que fijaban dichos criterios. De este modo, para el período histórico en que se desenvolvió la "Escuela Cuzqueña" las élites (clero, comitentes o quienes encargaban la pintura y notables) entendían que esas expresiones artísticas eran "pintura".

Pero, ¿qué se entendía por "pintura" en el virreinato peruano de aquella época? Por un lado, y debido al Concilio de Trento (1545-1563) — cuyas conclusiones para la prédica del evangelio en el Perú se plasmaron en el Catecismo de 1584 - se sostenía que los instrumentos privilegiados para la prédica del evangelio entre los antiguos vasallos del incario eran tres:

1) Los sermones.

2) Las obras teatrales, en especial los llamados "auto sacramentales".

3) Las artes plásticas, entre ellas, la pintura.

Esta fue la primera función de la pintura en el mundo andino: la de instrumento para la evangelización de los indios: "La Iglesia se valió de las artes como mecanismo de evangelización y adoctrinamiento" (Martínez \& Díaz, 2019). De ahí la representación pictórica de la Inmaculada Concepción, la Trinidad, así como la presencia simbólica de Cristo durante la eucaristía. Esto crea una tradición pictórica sui géneris que en base a una serie de símiles busca ingresar en el imaginario andino, conceptos y elementos cristianos claves para la evangelización. Mientras en Europa el Renacimiento liberaba la imaginación del artista para crear obras que buscaban el goce estético, en el virreinato peruano la pintura estaba enmarcada dentro de la acción evangelizadora. Gisbert (1999) ha determinado que entre los principales símiles representados en las pinturas de la Escuela Cusqueña se encuentran:

- La pachamama asimilada a las vírgenes.

- Los señores del universo visible asimilados a los ángeles.

- El dios rayo asimilado a Santiago Mataindios

- Las sirenas o deidades del Titicaca asimiladas a demonios del pecado.

- El Hananpacha o "mundo de arriba" de la cosmología inca asimilado al cielo o paraíso. 
La segunda función de la pintura en el mundo andino, como lo han expuesto Alba y Penhos (2011), fue la de servir como instrumento de expresión y expansión del poder simbólico por parte de los españoles respecto al resto de la población y, ya en el mundo indígena, de los caciques o indios nobles respecto a los indios plebeyos. Lo que cumplía la doble función de presentar a los caciques frente a los españoles y criollos, como agentes intermedios entre la élite blanca y la indiada. En relación con los indios plebeyos, afirmaba la superioridad de los caciques sea por su vinculación con los antepasados incas o por su vinculación con la élite virreinal blanca.

\section{Evolución histórica de la pintura cusqueña}

Primer periodo: El manierismo y los orígenes de la pintura cusqueña

Lo que se conoce como "Escuela Cusqueña" o "Pintura Cusqueña" se remontaría al año 1585, cuando arriba al Cusco el sacerdote jesuita italiano Bernardo Bitti, un afamado pintor que introdujo el manierismo en el virreinato peruano (Stastny, 2013). Este estilo pictórico era dominante en la Italia de aquella época y sobresalía por el alargamiento y estilización de las representaciones, el resplandor frío de los colores y un gran dominio técnico de los escorzos. Este estilo se caracterizó por "gusto por el detalle, dinamismo de las formas, indumentarias lujosas y espacios arquitectónicos de gran magnificencia” (Rovira, 2010).

Durante sus dos estancias en la ciudad del Cusco, Bitti, recibió varios encargos artísticos, tales como: hacer el retablo mayor de la iglesia jesuita; pintar los cuadros "La Coronación de la Virgen" y "La Virgen del Pajarito", para la Catedral de Indios, adjunta a la Iglesia de la Compañía ${ }^{b}$ Entre 1592 y 1598, realizó nuevas pinturas: "La Asunción de María" para el Convento de la Merced del Cusco; "Los Misterios de la vida de Nuestro Salvador Jesucristo" y la "Imagen del Niño Jesús" para la Cofradía de los Indios (Balta, 2009).

Como ha señalado Statsny, durante el siglo XVI llegaron a Lima pintores extranjeros sea porque eran religiosos que venían a reforzar la evangelización con sus pinturas o sea porque eran artistas europeos en busca de un nuevo mercado: así llegaron Bernardo Bitti (1548-1610) y Angelino Medoro (ca. 1567-1606). "Es el primero de ellos quien tuvo la influencia más vasta, decisiva y penetrante... en Lima, Arequipa, Cusco, Juli, Ácora, Sucre y a su capacidad de comprender las necesidades pictóricas del nuevo continente..." (Stastny, 2013, p. 27). Bajo la

\footnotetext{
${ }^{\mathrm{b}}$ Ambos cuadros se destruyeron en el terremoto de 1650.
} 
influencia de Bitti y de sus discípulos directos es que surgió la llamada "Escuela Cusqueña" o "Pintura Cusqueña", con fuerte influencia del manierismo (Statsny, 2013, p. 27).

\section{Segundo periodo: influencia de la Escuela Flamenca y el Barroco italiano}

Tanto la muerte de los maestros mencionados como el arribo masivo al Cusco de estampas y grabados religiosos procedentes de Europa, sobre todo de Flandes, popularizó el estilo pictórico flamenco. Esta será entonces la segunda influencia en la Escuela Cusqueña. Esta, contrariamente a lo que pudiera pensarse, no era un estilo de vanguardia para la Europa de la época, sino que tenía una fuerte influencia de la pintura medieval tardía, especialmente el Gótico (Rovira, 2010, p. 84). El gótico se caracterizaba por representar "la veracidad de las cosas y las personas... Además, y con independencia de los valores estéticos, los pintores flamencos dieron a conocer la pintura al óleo..." (Rovira, 2010, p. 60).

En estas primeras décadas del siglo XVII, los cuadros de la Escuela Cusqueña toman y adaptan el antiguo estilo manierista a las exigencias estéticas de la pintura flamenca, aunque la temática sigue siendo similar a la del primer periodo: la evangelización y los retratos de las élites. Pero no sólo el estilo se modifica, sino que también los motivos iconográficos están inspirados en grabados europeos, aunque adaptados a la realidad americana.

Las características más resaltantes de este cambio en la pintura cusqueña, tendrá como protagonistas a Diego Quispe Tito (1611-d. 1681) y Juan Espinoza de los Monteros (a. 16551669), con quienes se dará el desarrollo de la representación de los paisajes en la pintura virreinal peruana, se privilegiarán los interiores domésticos y se crearán tipos humanos idealizados, rubios y alargados, que se harán presentes en las representaciones de vírgenes y ángeles.

La creatividad de estos pintores, en especial de Quispe Tito, tendrá una influencia decisiva en el desarrollo posterior de la pintura en el virreinato. Quispe y Espinoza supieron asimilar la técnica de sus predecesores y reelaborar un estilo propio, autóctono, por eso con ellos es que surgiría el estilo cusqueño (Statsny, 2013). Hacia la segunda mitad del siglo XVII llegan gran cantidad de grabados del maestro Pedro Pablo Rubens, uno de los exponentes máximos del barroco, con lo cual también arriba al Cusco este estilo, su tercera influencia: "Numerosas estampas inspiradas en sus composiciones dinámicas y turbulentas serán recibidas en toda la América española" (Statsny, 2013, p. 32). Uno de los pintores de la Escuela Cusqueña más representativos a de este periodo será Basilio de Santa Cruz Pumacallao. 


\section{Tercer periodo: la madurez de la Escuela Cuzqueña}

Para el siglo XVIII la "Escuela Cusqueña" se cierra sobre sí misma y, con las influencias manieristas, flamencas y barrocas, así como los grabados europeos que constituían muchos de sus modelos y las exigencias del nuevo mercado para las obras de arte religiosas y de retratos que surgió por aquella época, aparecerá un estilo propio. Los pintores más famosos de este periodo fueron Basilio Pacheco (a. 1738-1752) y Marco Zapata (a. 1748-1764). Con ellos la pintura cusqueña llega a su clímax:

Es el momento del encuentro consigo mismo [...] Es éste un arte irreal. La lección del idealismo renacentista ... es llevado ahora a un extremo totalmente irracional. Y los paisajes que en las estampas de Flandes eran fantásticos pero probables, son en esta pintura escenarios de fábulas idílicas desvinculadas de la naturaleza (Statsny, 2013, pp. 32-33).

\section{La perspectiva pictórica en la Escuela Cusqueña}

\section{La aspectiva}

Es una representación del espacio que está relacionada con una cosmovisión religiosa, en el que hay un "espacio simbólico". Este no es sólo un lugar en el que se representa algo, sino que es parte sistémica de una cosmovisión, supone que tanto el tiempo como el espacio son cíclicos y se renuevan. Desde el punto de vista sociológico y siguiendo al neomarxismo, esta manera de concebir el espacio se da en sociedades primitivas y pre modernas con modos de producción basado en el parentesco y comprende sistemas sociales tribales, asiáticos, despotismo y antiguo. Surge pues en la Edad de Piedra y llega hasta la Edad Media (Gombrich, 2002).

Un ejemplo de representación en aspectiva es la de la Virgen Theotokos, de la cultura bizantina, que data alrededor del año 600 d.C. Podemos observar en ella una representación planimétrica donde el fondo y la dimensión espacial no obedecen a patrones geométricos sino es casi inexistente.

\section{La prospectiva}

La prospectiva es antropocéntrica, parte de la auto conciencia del ángulo visual humano y determina el modo cómo vemos lo que nos rodea. Parte de que la realidad es finita, perceptible 
de modo imperfecto, no percibe las cosas realmente como son sino cómo los sentidos las captan-la doxa platónica—, se asume que el tiempo y el espacio están disociados. Por ejemplo, podemos visualizar simultáneamente dos objetos, pero espacialmente uno está más cercano o lejano a nosotros. Por lo anterior se sostiene que es secular. Es una concepción del espacio desde un punto de vista psicofisiológico.

Por otro lado, la percepción humana "desconoce" el espacio infinito. El espacio prospectivo no es homogéneo sino irregular, es "dado". Esto se debe a que la imagen retiniana es cóncava. Esto explica las "aberraciones marginales" en los bordes de las fotografías pues intentan plasmar en un plano una imagen que es en realidad curva. Esta prospectiva puede desarrollarse presentando espacios cerrados como abiertos finitos. Dentro del espacio abierto sus líneas de fuga son múltiples y el fondo suele ser neutro. Para señalar la lejanía se acude a una gradación del color, denominada esfumato o "impresionismo antiguo" (Gombrich, 2002)

La lejanía de los objetos, al momento de ser representadas, son determinadas por el “ángulo visual". Esto era tan obvio para los antiguos que Euclides, en su octavo teorema, sostiene que la diferencia aparente entre dos dimensiones iguales vistas a distancias desiguales está determinada por la relación de los ángulos visuales correspondientes. A esta perspectiva también se la llamó perspectiva naturalis. El punto de fuga en la antigüedad no es único sino múltiple y converge de a dos en diversos puntos de un vértice común.

\section{La perspectiva}

Aparece con el Renacimiento y aplica la geometría y la matematización del espacio para indicar las distancias y la distribución espacial. Fue uno de los principales aportes del Renacimiento (Ramírez, 2009). Las figuras están representadas en torno a un punto de fuga único, central o inclinado a uno de los lados, y a su vez con múltiples planos horizontales para indicar la distancia o separación. Un claro ejemplo es "La Virgen de las Rocas” (1483-1486) de Leonardo Da Vinci: el cuadro tiene un "punto de fuga" central y los diversos planos de la representación obedecen a diversas líneas horizontales.

\section{La representación espacial en la Escuela Cusqueña}

Cuando en la Europa Occidental de inicios del siglo XVI se impone la perspectiva geométrica, en la pintura cusqueña es posible encontrar obras que están compuestas con los tres tipos de ontología espacial. La aspectiva se ve, sobre todo, en los llamados "altares pintados". Un ejemplo es "Nuestra señora de Belén", pintura de la Escuela Cusqueña del siglo XVII. La 
prospectiva se aprecia, por ejemplo, en "San Juan de Dios con Donantes". Escuela Cusqueña, anónimo del siglo XVIII. La perspectiva geométrica se aprecia, por ejemplo, en "El Juicio Final” de Diego Quispe Tito (S. XVII).

\section{Estudio de caso: La última comunión de Santa María Egipciaca}

\section{Fuentes iconográficas y representación espacial}

La gran mayoría de los cuadros en la pintura cuzqueña se hicieron por encargo, y si bien en varias de ellas se han recogido figuras que venían de grabados europeos, los pintores cusqueños pusieron en sus representaciones una gran contribución de su propia imaginación. Ahora cabe hacer la pregunta: ¿Quién fue Santa María Egipcíaca? Vorágine (1994) cuenta que María Egipciaca fue una célebre prostituta egipcia que, impresionada por la gran cantidad de peregrinos que se embarcaban de Alejandría a Palestina para ir a Jerusalén y adorar la Santa Cruz, quiso también ir hacia allá. Ya en Jerusalén, quiso ingresar al templo, pero una fuerza invisible se lo impedía. Impresionada, arrepintiéndose de sus pecados oró a la estatua de la Virgen María que estaba ahí, e ingresar.

Con tres monedas de plata compró tres panes y se fue al desierto a vivir como anacoreta. Se alimentaba sólo de esos panes que nunca disminuían. Sus vestidos se deshilacharon y vivía desnuda, mortificando su piel con el sol del desierto. Cuarenta y siete años después fue encontrada por Zósimo, un fraile que había cruzado el Jordán y había peregrinado durante treinta días en el desierto. Descubriendo su desnudez con un manto que le proporcionó Zósimo le contó su historia y le pidió que, el siguiente jueves santo, se encontraran en la orilla del Jordán para recibir la comunión. Luego de recibir la comunión, se despidió de él pidiéndole que la visitara en el lugar donde vivía el siguiente jueves santo. Al acudir nuevamente, ella ya llevaba casi un año muerta, aunque su cuerpo se mantenía impoluto. Con ayuda de un león manso la sepultó en el desierto.

Las representaciones de la santa recuerdan su vida de anacoreta sostenida sólo por tres panes, la comunión a orillas del Jordán, y su entierro en el desierto por Zózimo con ayuda de un león. El grabado original fue de Jean Leclerc IV (1555-1621/1622), posteriormente Adriaen Collaert (1555-1623) realizó uno sobre la base del anterior. Estos grabados habrían servido de modelo a Basilio de Santa Cruz Pumacallo, de quien sólo se sabe que estuvo activo en el Cusco entre 1661-1700 (Lavarello, 2002, p. 380). Lo anterior habría servido de modelo para el lienzo de autor anónimo que nos ocupa.

En el grabado de Leclerc IV se observa a la derecha al fraile Zózimo portando un cáliz con el vino de la comunión, entre ambas figuras están los tres panes con los que sobrevivió 
María Egipciaca en el desierto. En el fondo del cuadro está el río Jordán y unos templos. En el lado izquierdo del cuadro se ve a María Egipciaca ya muerta siendo sepultada por Zózimo, quien figura con el cáliz, pues había acudido a darle nuevamente la comunión, con ayuda de un león. El grabado hace uso de la perspectiva geométrica y el paisaje representado es europeo. En el paisaje no hay aves.

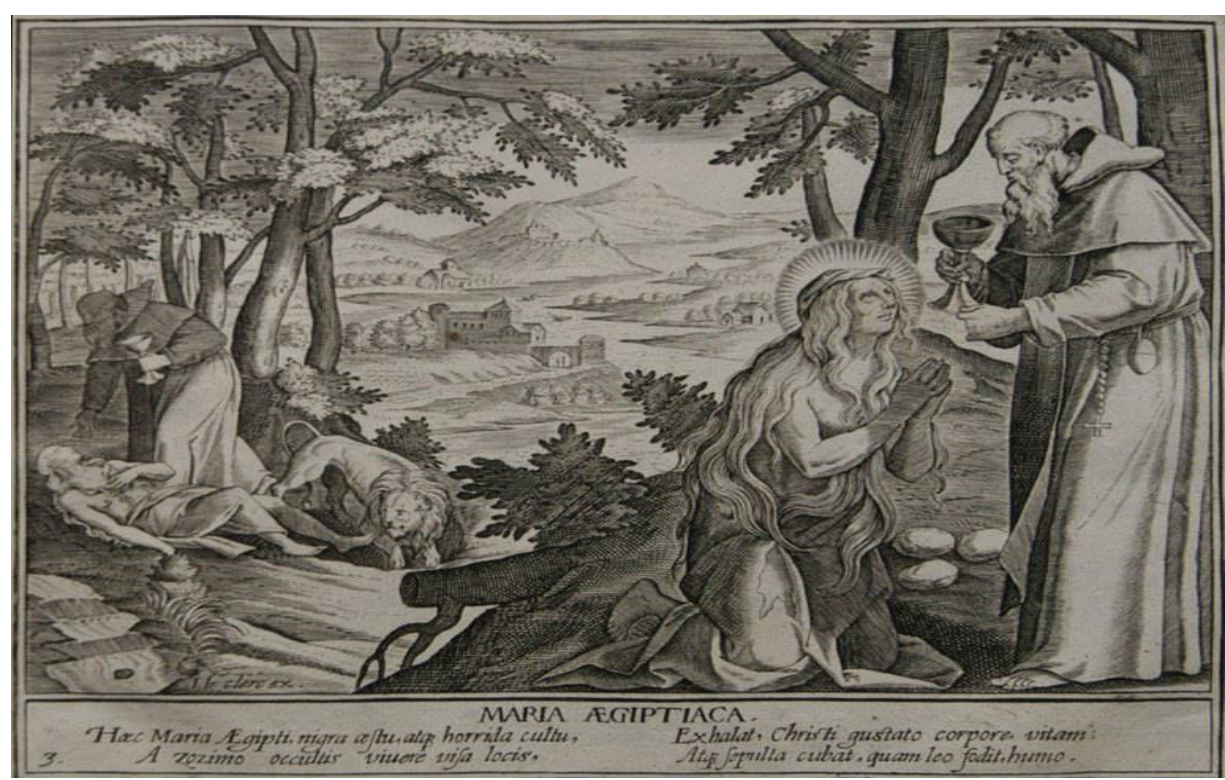

Tomado de PESSCA. Bajo licencia Creative Commons

En el grabado de Collaert se observa a la izquierda al fraile Zózimo portando un cáliz con el vino de la comunión, entre ambas figuras están los tres panes con los que sobrevivió María Egipciaca en el desierto. En el fondo del cuadro nuevamente están el río Jordán y unos templos. En el lado derecho del cuadro se ve a María Egipciaca ya muerta siendo sepultada por Zózimo, quien igual que en el grabado original figura con el cáliz, sepultándola con ayuda de un león. El grabado también hace uso de la perspectiva geométrica y el paisaje representado sigue siendo europeo. En el paisaje no hay aves. Sin embargo, la vegetación es mucho más frondosa que en el grabado de Leclerc IV. 


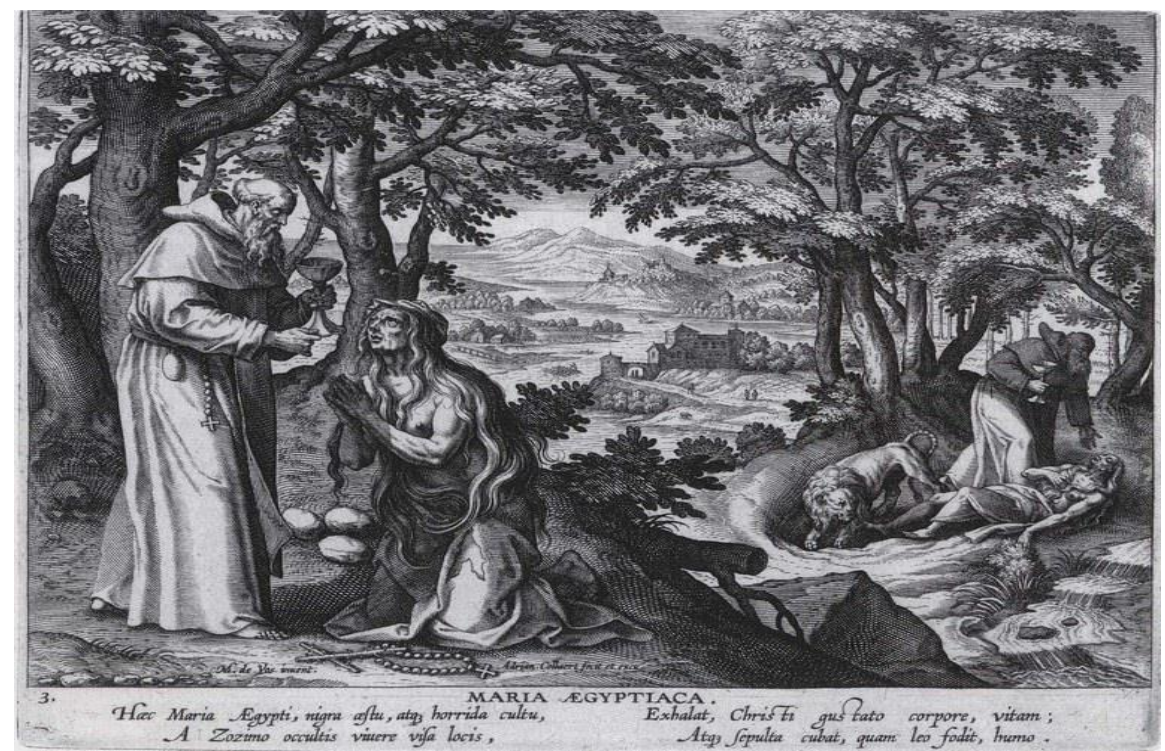

Tomado de PESSCA. Bajo licencia Creative Commons

Los mencionados grabados habrían influido en el lienzo de Santa Cruz Pumacallao. Sin embargo, éste sólo representa un detalle: la comunión de María Egipcíaca. Agregando a la escena dos ángeles que observan desde una nube. El paisaje también ha sido cambiado. No hay presencia de aves en la pintura.

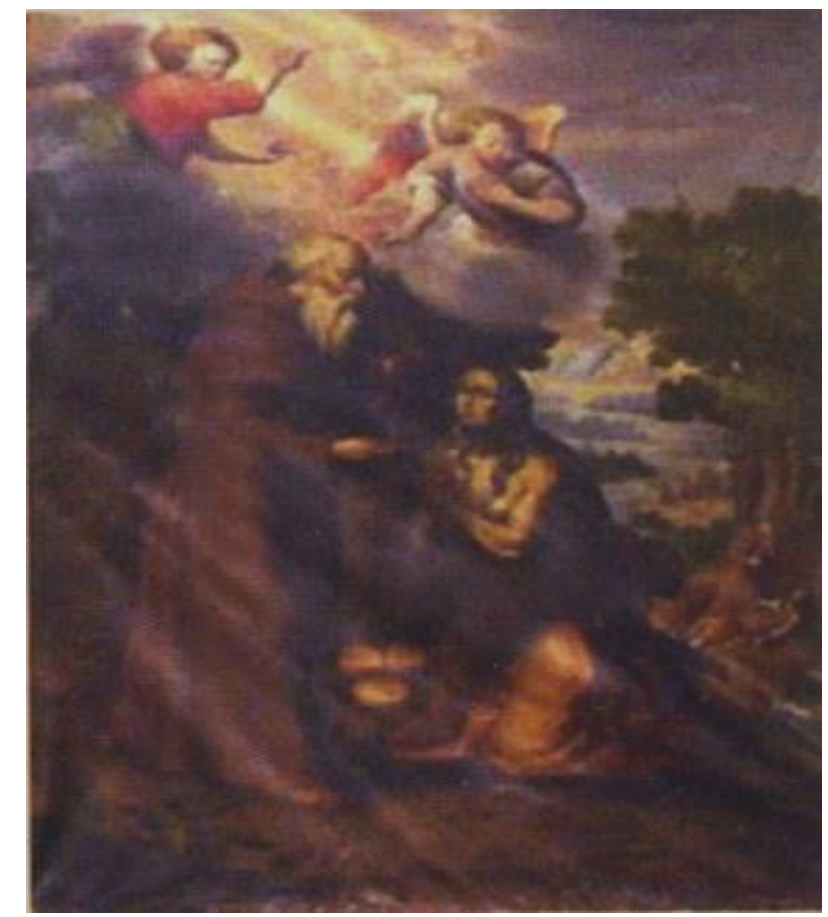

Tomado de PESSCA. Bajo licencia Creative Commons 
En el cuadro se observa, como en Leclerc, a la derecha, al fraile Zózimo portando un cáliz con el vino de la comunión, entre ambas figuras están los tres panes con los que sobrevivió María Egipciaca en el desierto, pero se ha agregado un cántaro desde donde se ha escanciado el vino en el cáliz. Adicionalmente, el pintor también ha agregado una gran cantidad de flores nativas. Al medio del cuadro, y ya no en el fondo, están el río Jordán, representado como un riachuelo, y una iglesia.

En el lado izquierdo del cuadro se ve a María Egipciaca ya muerta siendo sepultada por Zózimo, la está sepultando a la santa con la ayuda de dos leones. El cuadro hace uso de la perspectiva geométrica en la representación del paisaje y en entierro de la santa, pero en la representación de la derecha, donde le dan la comunión, la representación es más bien elaborada usando la representación perspectivista, pues están los personajes representados de modo planimétrico sin guardar una relación proporcional en la representación espacial con el resto del paisaje. El paisaje representado corresponde a la ceja de selva peruana.

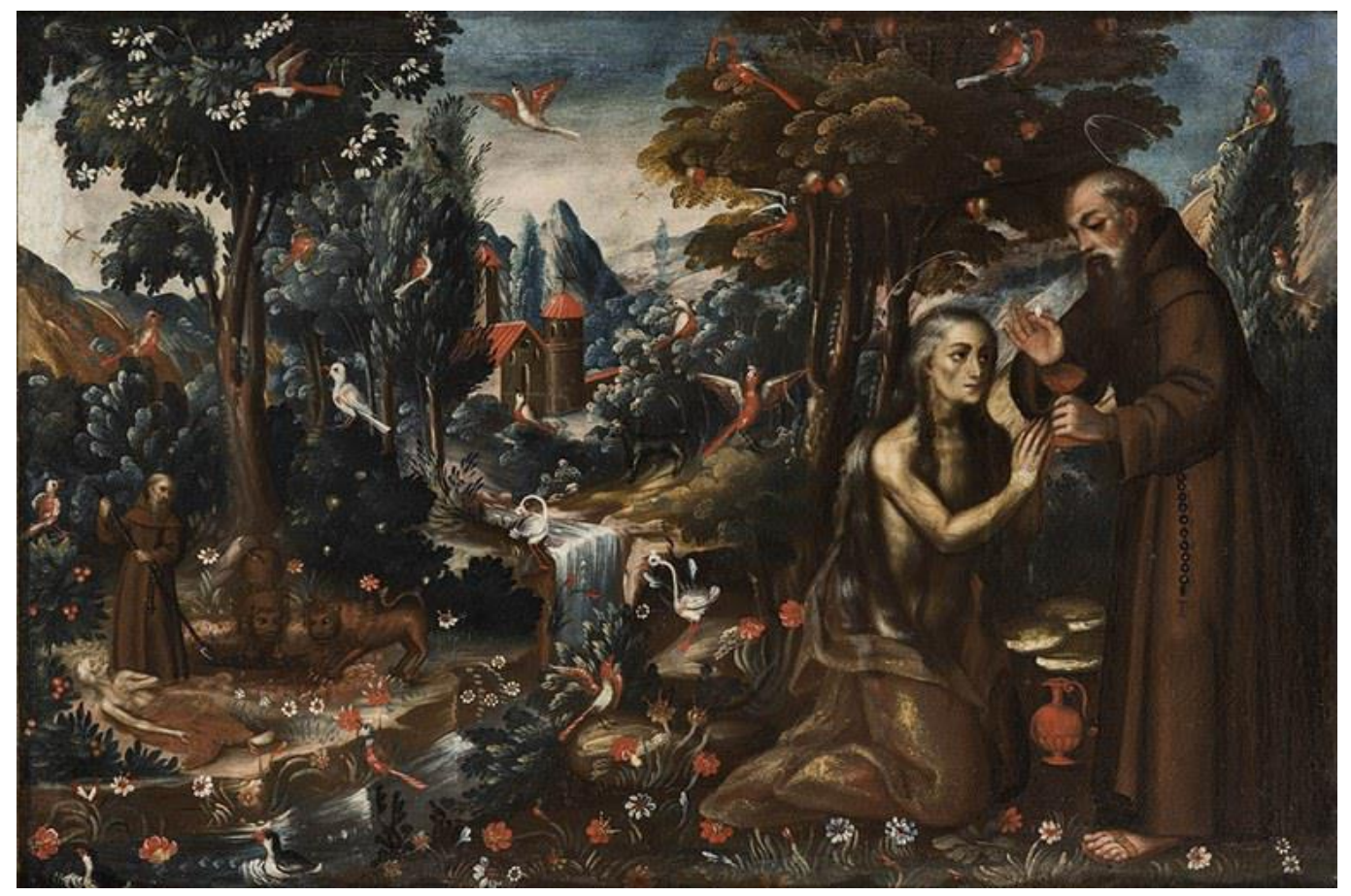

Tomado de PESSCA. Bajo licencia Creative Commons

En el caso estudiado más se observa una apropiación y redescripción del paisaje: ya no es un paisaje europeo como en los grabados originales sino un paisaje típico de la ceja de selva peruana. Se refuta de esta moda a Cohen (2015) para quien no hubo mayor innovación en la representación de los paisajes. 


\section{Las aves representadas}

La presencia de aves en el arte virreinal, ha tenido una gran importancia para el poblador nativo debido a que simbolizaba al plano superior del cosmos andino prehispánico, llamado Hanan Pacha (Torres, 2018). Por otro lado, el desarrollo de los estudios ornitológicos se inició en el noroeste peruano en el siglo XVIII, debido al interés del obispo de Trujillo Baltazar Jaime Martínez Compañón y Bujanda, quien entre 1779 y 1788, efectuó por primera vez la recopilación sistemática de información acerca de las aves peruanas, en láminas y acuarelas, las cuales fueron la manera más utilizada para recopilar representaciones en aquellos tiempos (Franke, 2007; Pulido, 2015).

En el imaginario zoológico, son frecuentes, las representaciones de animales como atributo de alegorizaciones diversas y donde resultan más usuales es en las personificaciones de carácter geográfico, como un componente de realidades físicas locales, nacionales o continentales, que se plasmaron en composiciones heráldicas de regiones (García, 2017). En este caso, los retratos de las aves buscan representar la fauna peruana. Estas pueden ser identificadas mediante comparaciones con especies existentes en la zona.

En la cosmogonía andina las aves tienen un lugar preponderante en el imaginario social. Por ello, los símbolos culturales que se otorgan a las aves, explican de algún modo el orden establecido en la sociedad y el Universo. Desde la ornitología no se puede aseverar a ciencia cierta que dichas representaciones pertenecen estrictamente a las especies que se identifican líneas abajo. Sin embargo, se han tomado varios indicadores para considerar: rasgos similares con la apariencia original, la especie habita en esa zona y el hábitat es el mismo. Por ello, el ámbito en el que las aves representadas son fruto de la encarnación de la realidad física del lugar o región (García, 2017).

En el caso del análisis del cuadro "La última comunión de Santa María Egipcíaca", la pintura de aves está inserta en una larga tradición que remite a la tesis del ya mencionado catecismo de 1584 en donde el "mundo de arriba" o "hanan pacha" se traduce no sólo por cielo, sino que se representa éste como "huerto florido": se pensaba que el Edén había estado en el nuevo mundo (Gisbert, 1999). Se identifica a las aves representadas en el cuadro:

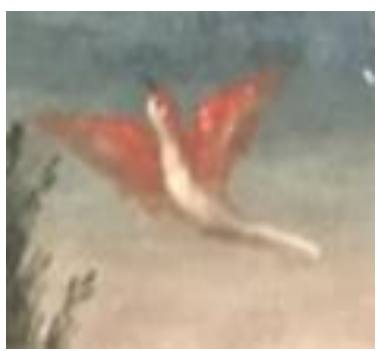

El ave del centro, de cuerpo blanco y alas ocre es idealizada como si fuera un espíritu. Se acerca a la morfología externa de una hirundinidae, golondrinas, que por la distribución geográfica podría ser Orochelidon murina, "golondrina de vientre pardo". 


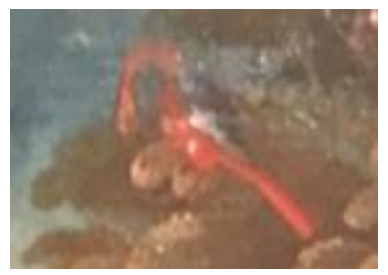

Se aproxima a un psittacidae, el "guacamayo rojo" por la coloración del plumaje podría ser Ara macao.

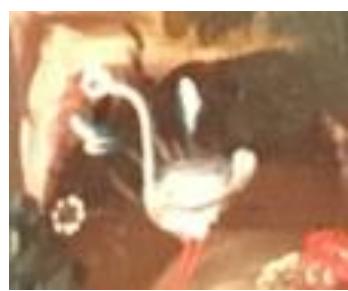

Puede ser una especie de threskiornithidae: "Espátula rosada" Ajaia ajaja, llamado también "pato cuchara"; aunque el ave real tiene el pico más largo al cual precisamente debe su nombre.

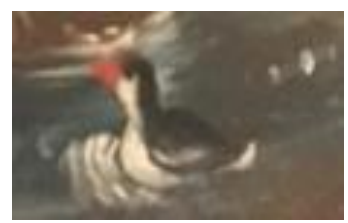

Un Anatidae que puede ser la "huallata" o "ganso andino" Chloephaga melanoptera, especie típica de los Andes que habita en los ambientes acuáticos.

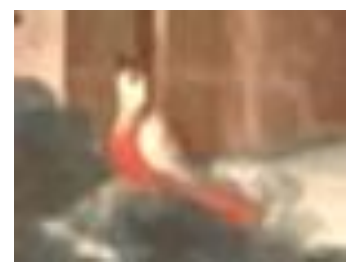

Una columbidae que podría ser la "paloma perdiz de garganta blanca" Geotrygon frenata, especie de amplia distribución en la vertiente oriental.

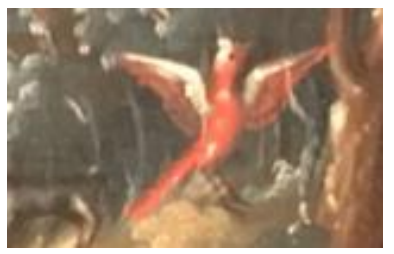

Una especie que podría pertenecer al orden cuculiforme, Сисо Piaya sp. ubicado en el árbol a la altura del hombro de la mujer.

En resumen, las especies que aparecen en el cuadro evidencian que existe una relación con las aves peruanas habitantes de la ceja de selva; lo que permite concluir que esta pintura cumpliría con el objetivo evangelizador desarrollando un universo simbólico afín al evangelizado nativo, trasladando el Paraíso y el Jardín del Edén al ambiente de la ceja de selva peruana. 


\section{Conclusiones}

Los cuadros de la Escuela Cusqueña tienen un significado simbólico relacionado o bien con la prédica del evangelio y la catequización o con la afirmación de las élites. Por lo que su función habría sido evangelizadora y, a la vez, legitimadora del orden social jerárquico del Perú virreinal. La representación pictórica utiliza una perspectiva variada: prospectiva y perspectiva geométrica. En la representación del paisaje se observa un punto de vista geométrico con un punto de fuga central, las imágenes tienen un tamaño y volumen variado para representar la mayor o menor distancia respecto al espectador y entre ellos, etc.

En la representación de la comunión de María Egipciaca las figuras son muy grandes para guardar relación espacial con el resto del cuadro y están en un primer plano sin mayor profundidad. Las aves representadas en el cuadro "La última comunión de Santa María Egipcíaca" pertenecen a la fauna de la Ceja de Selva Peruana, con lo que el artista y/o comitente buscarían facilitar la comprensión, en el plano simbólico del paraíso, al presentar este como un Jardín del Edén con elementos reconocibles por los espectadores (nativos en proceso de catequización o ya cristianizados).

\section{Referencias}

Alba, M. \& Penhos, M. (2011). Los cuerpos del poder en los andes: la momia y el retrato. Memoria del VI Encuentro Internacional sobre Barroco. Fundación Visión Cultural. https://www.academia.edu/17464051/2011_Los_cuerpos_del_poder_en_los_Andes_la _momia_y_el_retrato

Balta, A. (2009). El sincretismo en la pintura de la Escuela Cuzqueña. Cultura, 23, 001-100. https://www.revistacultura.com.pe/revistas/RCU_23_1_el-sincretismo-en-la-pinturade-la-escuela-cuzquena.pdf

Berger, P. L. y Luckmann, T. (1972). La construcción social de la realidad. Argentina: Amorrortu Editores https://zoonpolitikonmx.files.wordpress.com/2014/09/laconstruccic3b3n-social-de-la-realidad-berger-luckmann.pdf

Beuchot, M. (2009). La semiótica. Teorías del signo y el lenguaje en la historia. México: Fondo de Cultura Económica.

Caralt, M. \& Casal, F. (2012). La historia del arte explicada a los jóvenes. Barcelona: Editorial Paidós.

Cohen S. A. (2015). Pintura Colonial Cusqueña. El esplendor del arte en los Andes. Cusco: Huaynanca Editores.

Danto, A. C. (2013). Qué es el arte. Barcelona: Editorial Paidós. 
Del Valle, A. (2013). Poesía y mentira. La crítica de Platón a las poéticas de Homero, Hesíodo y Píndaro en el Ión y en República 2. Areté, 5, 55-162. http://revistas.pucp.edu.pe/index.php/arete/article/view/6395/pdf

Eco, U. (2013). Apocalípticos e integrados. Barcelona: Tusquets. https://monoskop.org/images/c/c4/Eco_Umberto_Apocalipticos_E_Integrados_1984. pdf

Franke, I. (2007). Historia de la ornitología peruana e importancia de las colecciones científicas de aves. Revista Peruana de Biología, 14, 159-164. https://revistasinvestigacion.unmsm.edu.pe/index.php/rpb/article/view/2182/1894

García, J. (2017). Un bestiario para celebrar: fauna simbólica en la fiesta barroca del virreinato del Perú. $\quad$ Quiroga 30-41 https://revistaseug.ugr.es/index.php/quiroga/article/viewFile/16289/13845

Gisbert, T. (1999). El paraíso de los pájaros parlantes. La imagen del otro en la Cultura Andina. La Paz: Plural Editores.

Gombrich E. (2012) Fórmula y experiencia. Arte e Ilusión. Estudios sobre la psicología de la representación pictórica. Phaidon. http://blogs.fad.unam.mx/asignatura/adriana_raggi/wpcontent/uploads/2013/01/gombrich.pdf

Hausser, A. (1977). Sociología del arte. Madrid: Editorial Guadarrama. https://www.academia.edu/14950675/Arnold_Hauser_Sociologia_del_Arte

Hernández, R. \& Mendoza, C. (2018). Metodología de la Investigación: las rutas cuantitativa, cualitativa y mixta. México: McGraw-Hill/Interamericana Editores.

Lavarello, G (2002). Artistas plásticos en el Perú. Lima: Editorial Pacasmayo.

Martínez, P. \& Díaz, A. (2019). Entre el cielo y el infierno: cofradías de indios en el Cusco y el programa iconográfico de las postrimerías (siglos XVI y XVII). Estudios Atacameños, 61, 49-71. https://dx.doi.org/10.4067/S0718-10432019005000103

Montes de Oca, E. (2010). Leonardo da Vinci, un gran artista del Renacimiento. La Colmena, 68,19-29. https://www.redalyc.org/pdf/4463/446344469003.pdf

Panofsky, E. (1980). La perspectiva como forma simbólica. Barcelona: Tusquets. https://monoskop.org/images/e/e6/Panofsky_Erwin_La_perspectiva_como_forma_si mbolica.pdf

Panofsky, E. (2016). Idea. Contribución a la historia de la teoría del arte. Madrid: Cátedra.

Pomella, A. (2004). Caravaggio, los caminos del arte. Roma: ATS Italia. 
Pulido, V. (2015). Apuntes históricos sobre el desarrollo de la ornitología en el Perú. Exégesis, 6, 133-146. http://revistas.uigv.edu.pe/index.php/exegesis/article/view/29

Ramírez, M. (2009). La perspectiva artificial y su influencia en el desarrollo de la fotografía: De la perspectiva artificial a la perspectiva fotográfica. Aisthesis, 45, 25-38. https://dx.doi.org/10.4067/S0718-71812009000100003

Rovira, A. (2010). Cómo reconocer estilos en la pintura. Arte y personalidad. Barcelona: Norma.

Stastny, F. (2013). Estudios de arte colonial. Lima: Instituto Francés de Estudios Andinos.

Torres, R. (2018). La pervivencia de la representación cosmológica del ave y felino andinos en el arte virreinal peruano sur andino del siglo XVIII [Tesis de Maestría, Universidad Nacional de San Agustín de Arequipa] http://repositorio.unsa.edu.pe/bitstream/handle/UNSA/10021/UPtopirm.pdf?sequenc $\mathrm{e}=1 \&$ is Allowed $=\mathrm{y}$

Venero, J. L. (2019). "Lucre - Huacarpay”: humedal mesoandino. Yachay - Revista Científico Cultural, 7 $(01)$, 516-520. https://revistas.uandina.edu.pe/index.php/Yachay/article/view/115/81

Von der Walde, G. (2006). Inspiración y conocimiento en Homero y en el ion de Platón. Estudios de Filosofía, (34), 95-107. http://www.scielo.org.co/scielo.php?script=sci_arttext\&pid=S0121$36282006000200006 \& \operatorname{lng}=$ en $\&$ tlng=es

Walker, B. (2015). Field guide to the birds of Machu Picchu and the Cusco Region Peru. Lynx Edicions, https://www.lynxeds.com/es/producto/field-guide-to-the-birds-of-machupicchu-and-the-cusco-region-peru/

Wölfflin, H. (1979). Conceptos fundamentales de la historia del arte. Madrid: Espasa-Calpe. https://issuu.com/jorgecarlosalvinololi/docs/wolfflin-conceptos-fundamentales-de 